\title{
Renal Calculi, CTCAE
}

National Cancer Institute

\section{Source}

National Cancer Institute. Renal Calculi, CT CAE. NCI Thesaurus. Code C143806.

A disorder characterized by the formation of crystals/kidney stones in the pelvis of the kidney, 